Revista Mídia e Cotidiano

ISSN: 2178-602X

Artigo Seção Temática

Volume 14, Número 2, maio-ago. de 2020

Submetido em: 14/04/2020

Aprovado em: 15/05/2020

\title{
Grande sertão: veredas e "Sertão grande": escrita e (re)significação na interface entre literatura e jornalismo
}

\section{Grande sertão: veredas and "Sertão Grande": writing, meaning, and the interface between literature and journalism}

\author{
Daniela Martins Barbosa COUTO ${ }^{1}$ \\ Rita Aparecida da Conceição RIBEIRO²
}

\section{Resumo}

Este artigo é sobre o sertão que surge na zona de contato entre a obra Grande sertão: veredas, de João Guimarães Rosa, e a série de reportagens "Sertão grande", produzida pelos repórteres Paulo Henrique Lobato e Luiz Ribeiro ${ }^{3}$, com fotografias de Alexandre Guzanshe, publicada em março de 2012 pelo jornal "Estado de Minas". O romance de Guimarães Rosa é o pano de fundo para o paralelo econômico estabelecido nas matérias entre o sertão do século XX e o do século XXI. A presença do texto literário na tessitura dos textos jornalísticos, junto ao design editorial, constroi o sertão no limiar entre fato e ficção, através do relato do viajante - seja ele o escritor, seja ele o repórter - e do discurso gráfico da página impressa. Nesse interdiscurso, que alia realidades distintas, emerge um sertão em cujo tecido social ainda há muito o que se fazer.

Palavras-chave: Design Editorial. Grande sertão: veredas. Jornalismo Impresso. Literatura.

\section{Abstract}

This article is about the hinterland that appears in the contact zone between the work Grande sertão: veredas, by João Guimarães Rosa, and the series of reports "Sertão

\footnotetext{
${ }^{1}$ Professora nos cursos de Jornalismo e Publicidade e Propaganda da Universidade do Estado de Minas Gerais (UEMG - unidade Divinópolis). Doutoranda em Design pela Escola de Design da UEMG; mestre em Letras, pela UFSJ. Graduação em Comunicação Social (Jornalismo e Publicidade \& Propaganda) pela UEMG. E-mail: danielambc@gmail.com. ORCID: 0000-0002-1248-1900.

${ }^{2}$ Coordenadora do Programa de Pós-Graduação em Design da Escola de Design da Universidade do Estado de Minas Gerais (UEMG). Líder do grupo de pesquisa do CNPq Design e Representações Sociais e pesquisadora do Centro de Estudos em Design da Imagem.e integrante do Grupo de Pesquisa Presente Y Futuro Del Diseño, da Universidad de Palermo, Argentina. Mestre em Comunicação Social pela UFMG e doutora em Geografia, pela UFMG. E-mail: rribeiroed@ gmail.com. ORCID: 0000-0003-0748-854X.

3 O repórter Luiz Ribeiro participou de três das nove reportagens da série "Sertão grande", sendo elas: "Veredas do novo sertão" e "Riqueza escondida no broto da terra", ambas em coautoria com Paulo Henrique Lobato e publicadas no dia 25 de março de 2012; e, "Frutas e pedras dão nova cor ao cerrado", publicada no dia 30 de março de 2012.
} 
grande", produced by the reporters Paulo Henrique Lobato and Luiz Ribeiro, with photographs by Alexandre Guzanshe, published in March 2012 by the newspaper "Estado de Minas". Guimarães Rosa's novel provides the backdrop for the economic parallel established in the articles between the 20th century and the 21st century backlands. Coupled with editorial design, the presence of literary texts in the fabric of journalistic texts positions the 'sertão' on the border line between fact and fiction. This is achieved by offering the traveler's account - whether he is the writer, or the reporter - and with the presentation of the printed page's graphic discourse. This interdiscourse combines different realities, revealing a hinterland marked by an incomplete social fabric.

Keywords: Editorial Design. Grande Sertão: veredas. Print journalism. Literature.

\section{As palavras, o sertão}

Pelos discursos que chegam através dos mais diversos meios, sejam eles eletrônicos ou impressos, o mundo ganha significados que, por sua vez, são construídos por diferentes olhares e formas. A palavra que, tempos atrás, se referia a uma coisa, tempos depois, pode dizer outra, como acontece com o sertão. No romance Grande sertão: veredas, de João Guimarães Rosa, lançado em 1956, "lugar de sertão não se divulga: é onde os pastos carecem de fechos; onde um pode torar dez, quinze léguas, sem topar com casa de morador" (ROSA, 2006, p. 8). Mas, na série de reportagens "Grande sertão", composta por nove matérias veiculadas entre 25 e 31 de março de 2012, no caderno de Economia do jornal "Estado de Minas", "o sertão não pára ( sic) de atrair pesados aportes" (LOBATO, 2012, p. 16).

Observa-se, segundo Oliveira e Caetano (2011), que o jornal "Estado de Minas" apresenta grande variedade de temas, tanto regionais quanto nacionais, tendo, a editoria de economia como uma de suas áreas que é bem consolidada. O periódico tem grande tradição no estado e integra o Grupo Associado Minas (Diários Associados). Foi fundado em 1928 e, "mesmo tendo perdido espaço, continua sendo o jornal de maior influência" (OLIVEIRA; CAETANO, 2011, p.10). Considerando esse contexto, avalia-se que a inserção de uma obra literária canônica como Grande Sertão: veredas para o desenvolvimento de matérias jornalísticas de economia amplia o campo de discussão do romance para além da arte, literatura, gramática, educação, biologia, história, geografia, enfim, áreas nas quais o romance roseano já foi exaustivamente discutido. 
No caso aqui apresentado, há ainda uma singularidade: o texto das reportagens é construído não só tendo a obra literária como pano de fundo para o contexto social e econômico do sertão, mas também como fonte da qual personagens, falas e citações são retiradas para compor as narrativas em contraponto com as realidades apuradas pelos repórteres Paulo Henrique Lobato e Luiz Ribeiro. Vista em panorama, a séria apresenta discussões que vão desde a devastação das áreas típicas de cerrado para plantio de eucalipto, passando pela exploração de gás no subsolo, até questões relacionadas à infraestrutura rodoviária e ferroviária, além de questões relacionadas ao comércio varejista, agricultura e acesso à educação.

A última reportagem apresenta esse panorama. Na margem externa, em foto/legenda, há a imagem da página de cada um dos dias em que a série foi publicada junto à síntese da reportagem (Fig. 1). Esse conjunto reforça, pelo título, que os lugares percorridos, pela reportagem e pelos personagens, são reais, pois integram os "caminhos de Rosa" (LOBATO, 2012, p.14).

A leitura em sequência temporal dos títulos e das imagens - "Novos caminhos de Rosa"; "Sertão grande" (manchete); "Veredas do novo sertão"; "Pó que não vem mais do chão"; "Riqueza escondida no broto da terra"; "Comércio agora mantém o sertanejo em casa"; "Cavalos agora vão no motor"; "Estradas trazem dinheiro e tragédia"; "Trem levou as pessoas e deve trazer o minério"; "Frutas e pedras dão nova cor à paisagem"; e, "Pobreza parece mais perene que os rios" - permite perceber como o sertão contemporâneo está diferente do sertão conhecido por Guimarães Rosa, mas, ao mesmo tempo, semelhante: ainda que haja a possibilidade de riqueza e de desenvolvimento social e econômico, a realidade ainda se apresenta com bastante desigualdade social.

E, para pensar essa interação entre literatura e jornalismo, recorre-se ao limiar, figura de pensamento discutida por Walter Benjamin apud Gagnebin (2010), que reflete, ao mesmo tempo, a diferença e o encontro entre duas coisas, como o instante de transição entre dia e noite ou, mesmo, a soleira da porta, lugar fluido, sendo, ao mesmo tempo, o ponto em que fronteira e passagem se encontram. No contexto da série, o papel do limiar é tornar visível o movimento constante entre fato e ficção, ou seja, entre o que realmente acontece e é "sentido na pele", e o que é fruto da imaginação. Ele promove a intersecção entre duas realidades distintas, tanto no tempo (1952-2012), quanto na sua constituição - 


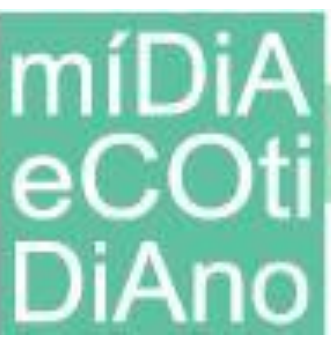

uma, é produto jornalístico; a outra, literário -, e faz com que o sertão possa ser significado através de seus opostos. No entanto, no caminho que os interliga, está a linguagem jornalística, que se apropria de trechos literários para demonstrar que esse espaço, conforme Bolle (2004) já observava, é mesmo uma construção labiríntica, que revela o quanto também são labirínticas as engrenagens sociais e econômicas.

Figura 1 - Caminhos de Rosa - síntese das reportagens publicadas na série "Sertão grande"
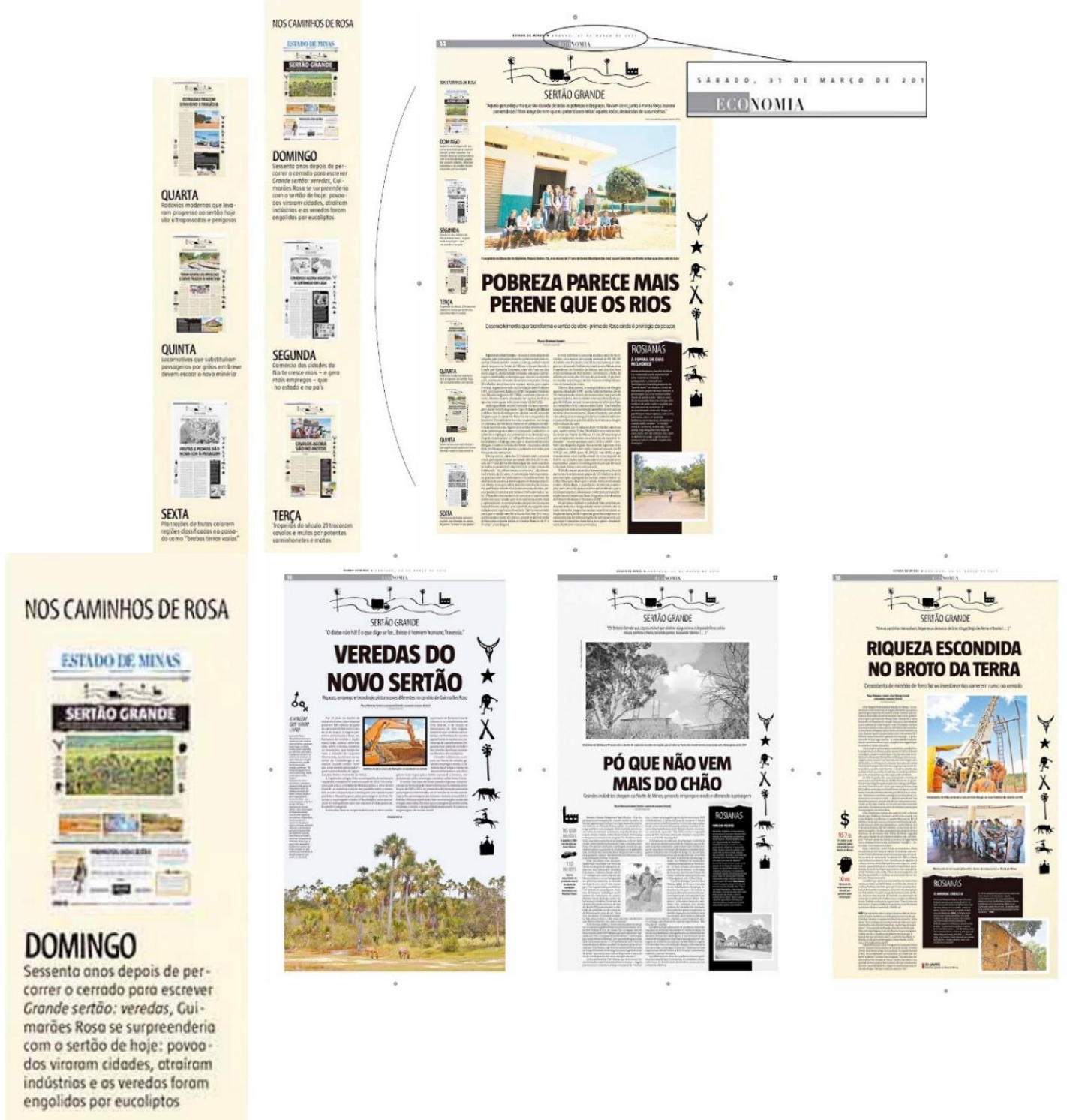


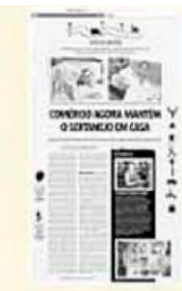

SEGUNDA

Comércio dos cidades do Norte cresce mois - e ger
mois empregos - que no estado e no pois

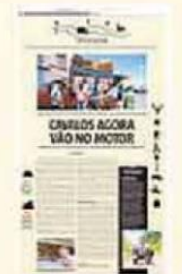

TERÇA

Tropeiros do século 21 trocorom covalos e mulos por potentes caminhonetes e motos

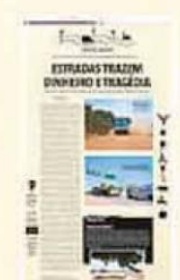

QUARTA

QDARTA Rodovios modernos que leva. romm progressso ao serțóo hoje

Fonte: Jornal "Estado de Minas", 31 de março de 2012.

Diante desse contexto, duas páginas sintetizam essas contradições: uma é a capa do jornal, que abre a série, no dia 25 de março de 2012, e, a outra é a última reportagem, "Pobreza parece mais perene que os rios", veiculada dia 31 de março de 2012, e que constituem, pois, o recorte deste artigo. Quanto à produção, seis décadas separam o texto literário do jornalístico, enquanto a linguagem, elemento comum a ambos, os unem na medida em que estabelece o romance, que é ficcional, como referência para o contraponto das "realidades" apuradas pela equipe de jornalismo.

A viagem de João Guimarães Rosa pelo interior de Minas Gerais, em 1952, que contribui com a escrita de Grande sertão: veredas, inspirou a produção da série jornalística, produzida, em 2012, para o caderno de "Economia". Observa-se que a literatura está, em geral, presente em outras editorias, entre elas, "Artes", "Educação", "Cultura" e "Gerais". Mas, ao deslocá-la para as páginas de Economia, os repórteres humanizaram a narrativa a respeito da situação social e econômica do sertão mineiro. Para isso, percebe-se que foram utilizadas as seguintes estratégias:

1) Comparação entre o presente e o passado, ou seja, entre o real apurado durante a produção da reportagem e o contexto narrado no livro;

2) Interação entre entrevistas com pessoas reais e falas de personagens fictícios do romance, ora também entendidas como falas de Rosa - "o autor sabia que a região estava prestes a mudar. Em Grande sertão: veredas profetizou [...] cidade acaba como sertão. Acaba?" (LOBATO; RIBEIRO, 2012, p.16) -, dando a entender que o escritor também se faz ouvir através da voz dos personagens que cria; 
3) Inserção de citações diretas e indiretas de Grande sertão: veredas na construção do texto jornalístico; e,

4) Elaboração de comentários, tendo por fundamento, situações narradas no livro, como pode ser percebido no trecho a seguir:

Sessenta anos depois da viagem que Guimarães Rosa fez pelo interior para escrever Grande sertão: veredas, a desigualdade social ainda impera no Norte de Minas, área conhecida a fundo por Riobaldo Tatarana, autor da frase no alto desta página ${ }^{4}$, destacada do romance em que o personagem arrebanha sertanejos que vivem na miséria para seu bando (LOBATO, 2012, p.14).

A objetividade do texto, marca da redação jornalística, se faz presente, mas, ela é construída no limiar entre realidade e ficção, pois quem conhece "a fundo" a região, é um personagem fictício, criado por Guimarães Rosa. Considerando o trecho acima, observa-se que o repórter parte do pressuposto de que Rosa fala através de Riobaldo e que essa fala é uma construção vinda das observações de Rosa, o que leva à percepção de que a reportagem transita entre realidade e ficção. No entanto, esse mesmo trânsito valida o argumento para que Grande sertão: veredas seja o cenário para traçar o paralelo entre a economia do sertão em 2012 com a de 1952, época em que João Guimarães Rosa viajou pelo interior do estado, durante dez dias, acompanhando boiadeiros entre Barreiro Grande e Araçaí. Vale lembar que essa viagem, segundo Costa (2006), rendeu anotações importantes para a escrita do romance.

Mas, diferente do jornalismo literário que, por sua vez, "utiliza recursos de observação e redação inspirados na literatura" tendo como "traços básicos imersão do repórter na realidade, voz autoral, estilo, uso de figuras de linguagem, digressão e humanização" (LABORATI; TEIXEIRA, 2009, p.1), o que se percebe na série de reportagens é a presença da interdiscursividade que articula informações do texto literário junto às do texto jornalístico, humanizando a narrativa, mas sem perder de vista os espaços enunciativos de cada uma. Tanto é que Lobato (2012, p.14), por meio de

\footnotetext{
4 “Aquela gente depunha que tão aturada de todas as pobrezas e desgraças. Haviam de vir, junto, à mansa força. Isso era perversidades? Mais longe de mim - que eu pretendia era retirar aqueles, todos, destorcidos de suas misérias" (ROSA apud LOBATO, 2012, p.14). Ver detalhe da Fig.4, no tópico "3. A Análise".
} 
determinados termos tais como "para escrever", "frase [...] destacada o romance" e "personagem", deixa transparecer esses diálogos entre literatura e jornalismo, de tal modo que o último atualiza o contexto social e econômico do primeiro. Como exemplos, demonstram isso o advérbio de circunstância - "ainda" - junto ao verbo no presente "impera", logo após a informação de que a desigualdade social continua, mesmo décadas após a viagem do escritor para escrever o livro.

Considerando a produção dos textos, o romance e as reportagens têm em comum o viajante significando o espaço - ora pela literatura, ora pelo jornalismo, ora pela ficção, ora pela factual, ora pela junção de ambos -; a duração da viagem (10 dias) pelo interior mineiro; e alguns lugares visitados, entre eles Brasília de Minas, Buenópolis, Buritizeiro, Corinto, Grão Mogol, Guaicuí, Paracatú e Paredão de Minas. A obra Grande sertão: veredas foi publicada pela primeira vez em 1956, quatro anos depois de Guimarães Rosa ter acompanhado a comitiva pelo sertão. Embora a escrita do livro tenha se concentrado entre a viagem do autor e o ano de publicação, Ana Luiza Martins Costa (2006) observa que o processo de elaboração vem de tempos anteriores à viagem de 1952 e abrange outras incursões por Minas Gerais, correspondências sobre o sertão entre Rosa e o pai, leituras diversas, anotações em cadernetas e memórias de infância em Cordisburgo, quando ele ouvia histórias dos tropeiros no comércio da família. A escrita é, pois, uma mescla de questões do sertão real com o imaginário.

Já segundo Willi Bolle (2004), Grande sertão: veredas é uma reescrita crítica de Os Sertões, de Euclides da Cunha: para ele, ambos "são discursos de narradores-réus-etestemunhas diante de um tribunal em que se julgam momentos decisivos da história brasileira" (BOLLE, 2004, p. 8), momentos esses relacionados à situação sociopolítica do país, que demonstram a falta de diálogo entre as classes altas e baixas, a luta pelo poder e pela ascensão social, além da exploração e violência. Mas Bolle (2004) também considera que o objetivo de Guimarães Rosa era caracterizar o sertão como lugar labiríntico e que o romance formava um mapa alegórico do Brasil. Em relação à palavra "sertão", observa-se que o termo, bem antes de chegar ao Brasil, já era usado na África e em Portugal e se referia a algo distante da costa: 
o vocábulo se escrevia mais frequentemente com c (certam/certão) do quem com s. [Gustavo Barroso] vai encontrar a etimologia correta no Dicionário da Língua Bunda de Angola, de frei Bernardo Maria de Carmecotim (1804), onde o verbete muceletão, bem como sua corruptela certão, é dado como locus mediterraneus, isto é, um lugar que fica no centro ou no meio das terras (GALVÃO apud BOLLE, 2004, p. 48).

Ainda hoje, quando se fala de sertão, a memória discursiva traz a imagem de um lugar ermo e distante, seco e sem muitos recursos. Mas, conforme Bolle (2004), o sertão do romance de Guimarães Rosa é "movimentante" todo o tempo, estabelece uma relação com a linguagem e se constrói, ainda, como lugar de memória e mapa de uma história social: "as dezenas de veredas desse mapa topográfico traçado a partir da rememoração de Diadorim desdobram-se em centenas de retratos de sertanejos e jagunços que Riobaldo (Guimarães Rosa) conheceu e criou" (BOLLE, 2004, p. 225).

O sertão dos textos jornalísticos também se movimenta, desdobra-se em dados econômicos, em personagens de carne e osso entrevistados pela reportagem, e se revela enquanto um espaço onde, ao mesmo tempo, "riqueza, emprego e tecnologia pintam cores diferentes no cenário de Guimarães Rosa" (LOBATO, 2012, p. 16), e a "pobreza parece mais perene que os rios" (LOBATO, 2012, p. 14) que, no romance, são muitos e aparecem em todos os caminhos percorridos por Riobaldo e Diadorim, tendo o Rio São Francisco, o rio da integração nacional, como curso divisor dos caminhos percorridos pelos personagens.

As antíteses - sertão vazio e cheio, seco e verde, rico e pobre - revelam tanto as contradições sociais de um mesmo país, considerando, segundo Bolle (2004), que o romance é uma alegoria das estruturas sociais brasileiras, quanto a multiplicidade sertaneja que se tece na zona de contato na qual viajantes e visitados se encontram, assim como ficção e factual se interagem. O termo zona de contato foi cunhado por Mary Louise Pratt (1999) no livro Os olhos do império, e discute como os sujeitos são constituídos nas e pelas suas relações com os outros e em espaços onde culturas díspares se encontram e se entrelaçam.

Dessa forma, o sertão tão pobre e vazio é, também, rico e repleto de veredas. Conforme Pratt (1999, p. 113), "o olho determina o que ele abrange em seu olhar" e, assim, na zona de contato, o observador interpreta em termos daquilo que, em 
determinado momento, se torna visível para ele e, ainda, segundo a bagagem sociocultural que constrói e traz consigo. Ele observa o outro do seu ponto de vista e o interpreta segundo seus critérios, dentro de um jogo no qual quem tem (ou aparenta ter) mais poder, dita as regras dentro das interações estabelecidas.

Uma 'perspectiva de contato' põe em relevo a questão de como os sujeitos são constituídos nas e pelas suas relações uns com os outros. Trata as relações entre colonizadores e colonizados, ou 'viajantes' e 'visitados', não em termos de separação ou segregação, mas em termos da presença comum, interação, entendimento e práticas interligadas, frequentemente dentro de relações radicalmente assimétricas de poder (PRATT, 1999, p.32).

As interações, que constroem a história do ponto de vista de quem retorna com coisas para contar - e que, portanto, segundo Pratt (1999), é quem estabelece o valor e o significado do que foi visto -, permeiam o espaço-tempo textual que, nas reportagens, é também o espaço-tempo de viagem. No romance, esse aspecto é multifacetado: o ir e vir das memórias de Riobaldo nem sempre fixam o espaço nem o tempo, pois a travessia é constante e as certezas do que foi não são tão certas assim. "O senhor vê. Contei tudo. Agora estou aqui, quase barranqueiro [...] Sei de mim? Cumpro" (ROSA, 2006, p. 607$608)$.

Para Pratt (1999), a história, por sua vez, é tanto a maneira como se imagina que ela é quanto a maneira como as coisas podem ser. E se no romance, as incertezas e o não saber sobre tantas coisas pairam sobre a rememoração de Riobaldo, nos textos jornalísticos, pelas relações discursivas (Fig. 2), elas se tornam tanto suposições quanto constatações sobre a realidade do espaço-tempo. "O sertão também tem grandes reservas de gás, já anunciadas por Riobaldo, protagonista do livro: 'Em um lugar da encosta, brota do chão um vapor de enxofre, com estúrdio barulhão, o gado foge de lá, por pavor" (LOBATO, 2012, p. 1). (Fig. 2). 


\section{míDiA

Figura 2 - Capa da série 'Sertão grande" e detalhe da citação direta na chamada

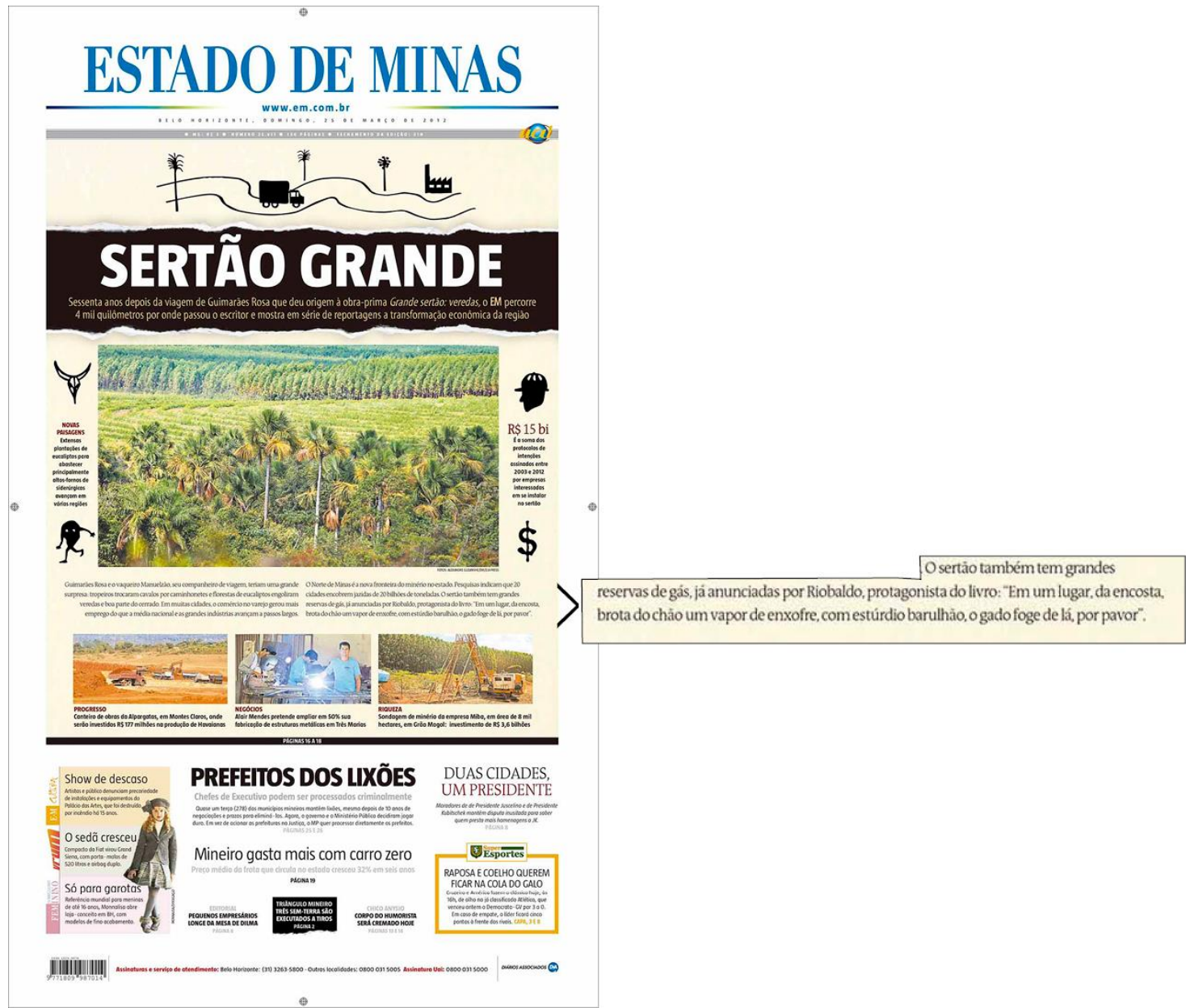

Fonte: Jornal "Estado de Minas”, 25 de março de 2012.

Nesse limiar entre fato e ficção, está a linguagem. No entanto, entre um texto e outro, não há apenas a diferença espacial e temporal de mais de meio século, mas um conjunto de condições de produção do discurso, inclusive gráfico, que fazem com que as narrativas sejam construídas de determinada forma e não de outra. Ainda que a linguagem seja a matéria prima tanto do texto literário quanto do texto jornalístico e preencha, discursivamente, as lacunas das histórias, ainda predomina o maniqueísmo ${ }^{5}$ entre ficção e fato, entre o que é do campo da invenção e do campo do relato tido como fidedigno (uma vez que a história, seja qual for, é contada através dos recortes feitos e pontos de vista adotados), mesmo que se trabalhe com formatos que se atualizam junto tecnologia, pois:

\footnotetext{
${ }^{5} \mathrm{O}$ termo está sendo empregado no sentido de polarização e divisão entre os conceitos.
} 
Para entender o que é e o que não é jornalismo, primeiramente é preciso definir sua estrutura e seus fundamentos [...] buscando na história da imprensa aquilo que é e permanece sendo essencial para a atividade. Fato é que o jornalismo sempre executou uma série de funções, sendo a informativa apenas uma delas [...] Jornalismo pós-industrial é um termo que resolve de maneira bastante eficiente os desafios e perspectivas do jornalismo no tempo presente, e os estudos buscam mapear e explorar dilemas com os quais ainda estamos nos enfrentando (COSTA, 2014, p.7).

Entre esses dilemas, estão os limiares entre as linguagens, não só enquanto matéria prima da comunicação, mas como elementos constitutivos de produtos. Em todo caso, o que permanece como pressuposto para o ofício do jornalismo, é o trabalho com a informatividade, com os fatos concretos e reais, entendidos na lógica da profissão enquanto conceitos que se contrapõem à ficção e à invenção. E, com a difusão da tecnologia, torna-se cada vez mais importante a demarcação dos espaços entre aquilo que é fato, acontecimento real, e o que é do universo da inventividade: é por meio dessa diferença que a credibilidade se constrói. Traquina (2005) já avaliava que o jornalismo deve se ater aos acontecimentos, pois a "transgressão da fronteira entre realidade e ficção é um dos maiores pecados da profissão de jornalista" (TRAQUINA, 2005, p.20). Já Hanzen (2015, p.2), ao atualizar essa discussão para tratar sobre as teorias da produção jornalística, observa que, ainda hoje, "a produção da informação, portanto, é, permeada por injunções econômicas, políticas, cultura profissional e subjetividade", mantendo a organização do campo jornalístico contemporâneo na interação entre o polo econômico, que define as notícias enquanto negócio, e o ideológico, que as considera enquanto serviço público. Também emerge, desse contexto, a discussão sobre a verdade, pois:

Seja com os relatos das factualidades (jornalismo), das ficcionalidades (literatura) ou aproximações (história), os narradores - escritores, jornalistas, historiadores, memorialistas etc - confeccionam seus textos orientados pela maior justeza em torno da verdade, seja pela ênfase no rigor semântico ou mesmo da sintaxe (MARTINEZ; CORREIO; PASSOS, 2015, p. 245-246).

Mas, caso se considere as discussões de Jacques Le Goff (2003), essa transgressão pode ganhar outro sentido. $\mathrm{O}$ autor observa que os documentos que constituem a História 


\section{míDiA

- e considerados como fatos - são construções que o historiador faz conforme as seleções que realiza tanto das fontes quanto dos trechos que serão registrados. Por essa perspectiva, o fazer jornalístico é também uma construção na medida em que seleciona fontes, recorta trechos de entrevistas, analisa o que pode e o que não pode ser dito e direciona o enfoque de cada matéria segundo a linha editorial do veículo de comunicação e, também, de acordo com os critérios adotados por quem decide o que será tratado pela mídia ${ }^{6}$. Diante disso, pode-se dizer que a série de reportagens "Sertão grande", ao utilizar Grande sertão: veredas como referência temporal para o paralelo econômico, torna o romance de Rosa um arquivo histórico e o atualiza conforme as circunstâncias de produção do discurso jornalístico: o interdiscurso, assim, concede o tom das narrativas.

\section{A análise na zona de contato}

A produção crítica sobre Grande sertão: veredas é bastante vasta - dos 5.703 registros do banco de dados bibliográficos sobre João Guimarães Rosa, da USP ${ }^{7}, 1.127$ se referem ao romance -, mas, mesmo assim, ainda há muito campo a ser explorado. A interface com o design é um deles, pois apenas dois trabalhos tratam disso, sendo um sobre design de moda, considerando uma coleção primavera-verão de Ronaldo Fraga, inspirada no romance, e, outro, sobre as ilustrações de Poty Lazzarotto para obras diversas de Guimarães Rosa.

Sobre a interação entre Grande sertão: veredas, jornalismo e design editorial, também tratada neste artigo, não há ainda nenhum trabalho catalogado nesse banco de dados. Considerando que a produção jornalística "Sertão grande" foi construída com base na obra literária, assim como a vinheta ${ }^{8}$ da série, pode-se perceber o quão relevante é o papel do design no processo de significação, pois:

O design de material editorial cumpre diferentes funções tais como dar expressão e personalidade ao conteúdo, atrair e manter os leitores, e estruturar o material de forma clara. Essas funções têm de conviver e

\footnotetext{
${ }^{6}$ Esses critérios variam conforme a teoria jornalística discutida. Ver: TRAQUINA, Nelson. Teorias do Jornalismo: porque as notícias são como são? 2a ed. Florianópolis: Insular, 2005.

${ }^{7}$ Disponível em: https://www.usp.br/bibliografia/inicial.php?s=grosa. Acesso em: 03 abr. 2020.

${ }^{8}$ Elemento gráfico-visual que acompanha uma produção impressa, eletrônica, audiovisual ou digital com a função de identificá-la.
} 
trabalhar juntas de forma coesa para configurar algo que seja agradável, útil ou informativo - geralmente, um combinação de todos os três, se é para ter sucesso. No seu melhor, o design editorial para material impresso e digital é um laboratório de pesquisa emocionante (CALDWELL; ZAPATERRA, 2014, p.10).

Tanto é que, nesse caso, outras áreas da comunicação visual, como o da arte e ilustração, foram adotados pelo projeto gráfico das reportagens, inclusive, para manter o diálogo com a obra literária de referência para o jornalismo. A vinheta (Fig. 3), que acompanha todas as reportagens da série, buscou inspiração nos mapas do sertão, ilustrados pelo artista plástico Poty Lazzarotto, sob orientação de João Guimarães Rosa, e inseridos nas orelhas da segunda edição do romance, tida como definitiva pelo autor e publicada em 1958.

Figura 3 - Inter-relação de elementos entre o mapa feito por Poty e a vinheta de "Sertão grande"

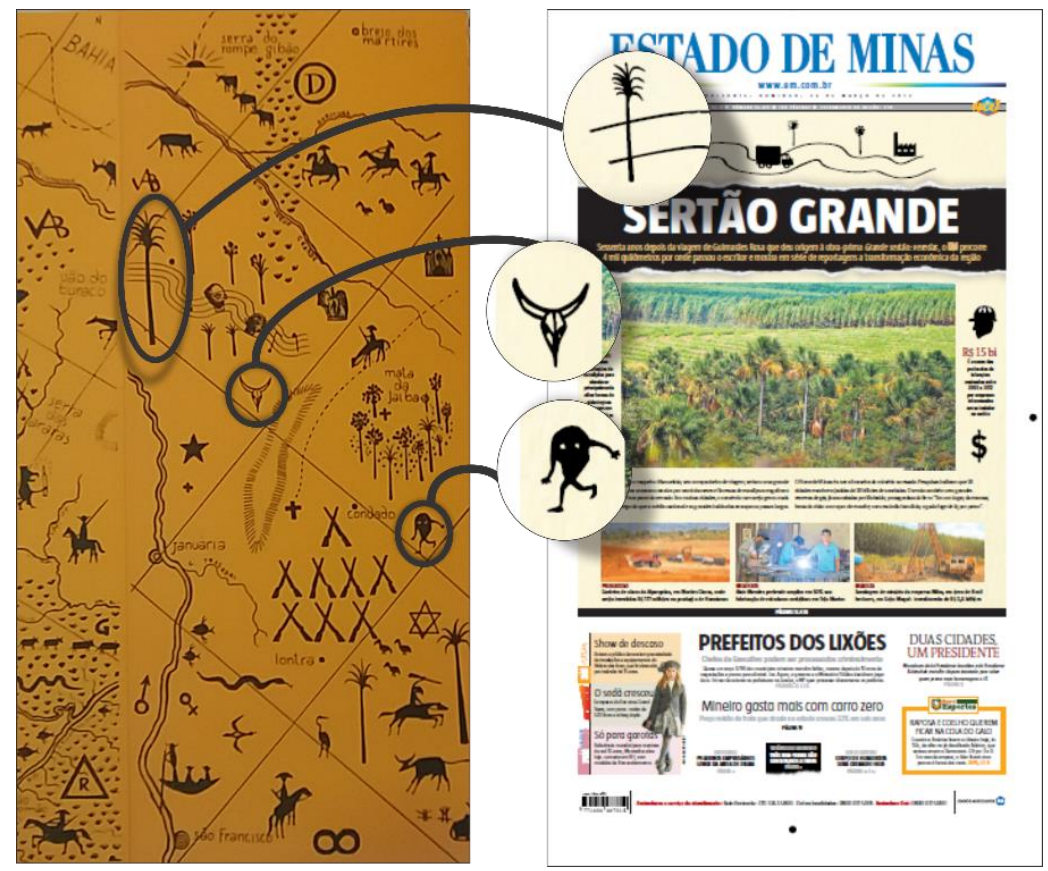

Fonte: Montagem do autor, tendo como referência os mapas ilustrados por Poty Lazzarotto, publicados nas orelhadas da $22^{\mathrm{a}}$ edição de Grande sertão: veredas, pela editora Companhia das Letras, em 2019, e capa da série de reportagens "Sertão grande", publicada pelo jornal "Estado de Minas", em março de 2012. 
Os elementos visuais do mapa, ao serem inseridos na página do jornal impresso, saem do universo imaginativo da literatura, e, nesse processo de deslocamento, passam por novo processo de significação: o buriti, a caveira de boi e a forma humana estilizada que, no livro, remetem, respectivamente, às veredas, à sequidão e ao místico, se tornam, na série jornalística, dada às interações com os demais elementos da página, referências à paisagem sertaneja, à miséria e ao desconhecido. Apenas o último elemento mantém relação com o contexto de origem, pois conserva o misticismo presente na obra, mas, ainda assim, é ressignificado, na medida em que representa o que é arcaico frente à modernidade que começa a preencher o sertão do século XXI.

Assim, por meio da leitura do romance, das reportagens e da observação do projeto gráfico, o que se percebe é uma dispersão dos discursos para a constituição de outros discursos. O sertão, onde "o gerais corre em volta" (ROSA, 2006, p. 8) é também “estes seus vazios. O senhor vá. Alguma coisa, ainda encontra" (ROSA, 2006, p. 31). E, além disso, é um cenário onde as mudanças tecnológicas chegam e modificam a paisagem, mesmo que não alterem tanto a situação social da região.

Guimarães Rosa se surpreenderia com o novo sertão: o povoado de Barreiro Grande cresceu e se transformou em Três Marias, o de Araçaí se emancipou de Sete Lagoas [...] Enquanto isso, parte do cerrado e das veredas deu lugar a extensas florestas de eucaliptos (LOBATO; RIBEIRO, 2012, p. 16).

O sertão é um composto de enunciados produzidos sobre condições variadas, com pontos convergentes e divergentes, mas, em todo caso, elaborados pelo olhar do homem da cidade que viaja pelo sertão - seja esse homem o escritor ou o repórter -, interage com as pessoas que vivem nesse lugar e volta com as histórias e entrevistas coletadas para, de outro espaço, narrar o que viu, viveu, imaginou e conclui. O sertão é também uma construção social ambígua, paradoxal, erguida na interface entre literatura e jornalismo, entre Grande sertão: veredas e "Sertão grande", naquilo que Pratt (1999) chamou de zona de contato, ou seja,

espaços de encontros coloniais no qual as pessoas geográfica e historicamente separadas entram em contato umas com as outras e 
estabelecem relações contínuas [...] Aqui, tomo emprestado o termo 'contato' de seu uso em linguística, onde a expressão 'linguagem de contato' se refere a linguagens improvisadas que se desenvolvem entre locutores de diferentes línguas nativas que precisam se comunicar entre si de modo consistente um com o outro, usualmente, no âmbito comercial (PRATT, 199, p. 31).

Um fenômeno complexo da zona de contato, de acordo com Pratt (1999), é a hospitalidade com que os visitados recebem os viajantes. Nessa interação, busca-se ter a validação das formas de saber de um sobre o outro. Em Grande sertão: veredas esse fenômeno pode ser percebido no monólogo que Riobaldo (o homem do sertão) estabelece com o doutor da cidade (o homem da metrópole): ora o personagem questiona o doutor da cidade - "Me concebo. O senhor não é como eu? Não acreditei em patavim" (ROSA, 2006, p. 9) -, ora busca confirmação de si mesmo por meio do outro - "Amável o senhor me ouviu, minha ideia confirmou [...] Amigos somos" (ROSA, 2006, p. 608).

Ainda conforme Pratt (1999), uma "perspectiva de contato" discute como os sujeitos são constituídos nas e pelas suas relações com os outros, e trata as relações entre viajantes e visitados, por exemplo, em termos de interação e práticas interligadas. A autora analisa que o relato de viagem e a exploração produziram o "resto do mundo" para leitores europeus em momentos particulares da trajetória expansionista da Europa. Do mesmo modo, pode-se dizer que tanto as reportagens - na medida em que se constituem pelo olhar do repórter sobre o fato tratado e, ainda, pela viagem que o jornalista fez ao interior mineiro -, quanto o romance, produzem o sertão para seus leitores, ainda que em momentos específicos e sob circunstâncias diferentes.

$\mathrm{Na}$ zona de contato, o texto literário e o texto jornalístico estabelecem entre si as relações discursivas que contribuem para a significação do sertão através do olhar do viajante, que recolhe casos e fatos e os reconstrói por meio da linguagem. Disso resultam espaços que se encontram em um limiar: na construção das reportagens, os lugares visitados são contextualizados com referências ao romance e seus personagens, breves resumos sobre eles e, por meio da construção textual, a interação com os fatos apurados é tecida.

Distrito de Buritizeiro, Paredão de Minas é o arraial onde ocorre a guerra final entre o bando de Riobaldo, o protagonista, e o liderado por Hermógenes e Ricardão, assassinos do 'grande chefe' Joca Ramiro [...] 
Todos os anos, fãs de Guimarães Rosa vão ao lugar para conhecer de perto o palco escolhido por ele para encerrar o romance. $\mathrm{O}$ desenvolvimento ainda não chegou ao pacato lugar, mas o lugarejo, com 1,5 mil habitantes não é um povoado fantasma, como descreveu Riobaldo em Grande sertão: veredas: 'o Paredão existe lá. Senhor vá, senhor veja. É um arraial. Hoje ninguém mora mais. As casas vazias [...] (LOBATO, 2012, p. 14).

Embora Grande sertão: veredas seja uma obra bastante conhecida e as reportagens sejam construídas tendo em mente o público leitor do jornal "Estado de Minas", é pela interdiscursividade, entendida pela perspectiva de Foucault (1999) como sendo interligações entre discursos dispersos no tempo e no espaço, que emergem conforme as condições de produção e, ainda, como as conexões de um texto com o outro. Considerando a linguagem enquanto mediadora das histórias e os fatos como interpretações, tem-se uma relação discursiva que, por algumas linhas, tece a narrativa no limiar da ficção e do factual, delimitando, todavia, os espaços entre as informações.

Para compor o cenário sertanejo dos anos 1950 e, também, preencher as lacunas dos fatos históricos, foram utilizados trechos de Grande sertão: veredas de forma que o texto literário se constituiu não apenas o contraponto, mas também, o pano de fundo, para o texto factual, conforme pode ser percebido na primeira reportagem da série (Fig. 4), que traz a contextualização do romance e a explicação sobre a produção do mesmo.

Para a série de reportagens, tanto a viagem de Guimarães Rosa, quanto a travessia dos personagens do romance, são considerados como realidades factíveis para a composição do paralelo com os fatos apurados em 2012.

\begin{abstract}
A viagem dos amigos, feita na companhia de outros seis vaqueiros, completa 60 anos em maio de 2012. Em comemoração à data, o "Estado de Minas" publica a série 'Sertão Grande'. As matérias traçam um paralelo entre a economia atual e a daquela época em lugares percorridos tanto por João [Guimarães Rosa] e Manuel quanto pelos personagens do livro (LOBATO, 2012, p. 16).
\end{abstract}

Acredita-se que esse contraponto se torna possível considerando a linguagem enquanto mediadora para a construção das histórias. Assim, parte-se do pressuposto de que toda realidade é uma elaboração linguística, que os fatos são interpretados por quem os vê, apura e relata, e, ainda, conforme as posições que assume e o lugar de onde fala. 


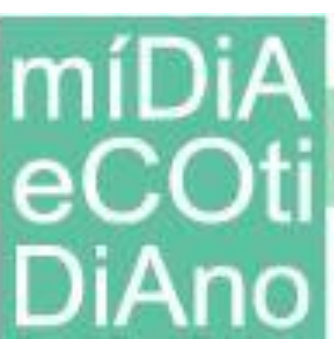

Figura 4 - Contextualização do romance enquanto elemento factual

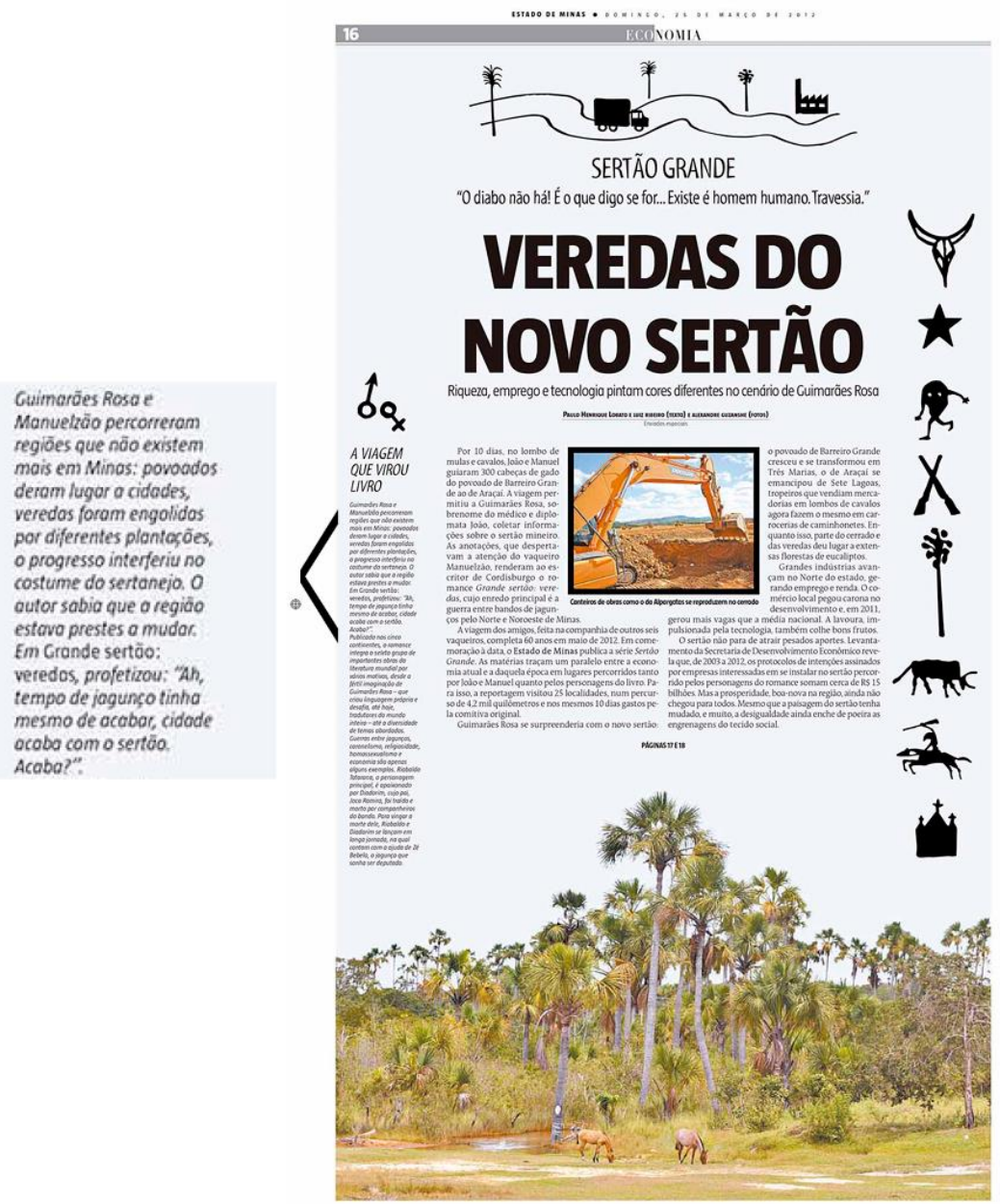

Fonte: Jornal "Estado de Minas”, 25 de março de 2012.

No caso do jornalismo, cabe lembrar também que a linha editorial do veículo e o espaço disponível na página do jornal são outros elementos que orientam - e, por que não, condicionam - a produção do discurso, pois conforme Foucault (1999), há as exclusões e as interdições, pois em "toda sociedade a produção do discurso é ao mesmo tempo controlada, selecionada, organizada e redistribuída por certo número de procedimentos que têm por função conjurar seus poderes e perigos" (FOUCAULT, 1999, p.8-9), ou seja, não se pode falar de tudo, nem se pode falar tudo: existe, no discurso, o "até onde se pode ir". 
Assim, conforme as circunstâncias em que se encontra, a prática discursiva se modifica e tece efeitos de sentidos que se voltam não para o conteúdo, mas para aquilo que permanece dele. Por isso, o sertão na zona de contato conserva elementos de ambos os espaços textuais que o compõe.

\section{O sertão no limiar entre literatura e jornalismo}

Não são apenas o tempo e as interações na zona de contato que transformam o sertão: os espaços também o modificam, além de outras condições tais como quem fala, de onde fala, em que circunstâncias e sob quais posições fala. Os modos de enunciar se constituem nesses feixes de relações e estabelecem as condições para o discurso. Conforme Foucault (1997), tais feixes podem ser entendidos como modalidades enunciativas e manifestam a dispersão do sujeito, ao invés de estarem relacionadas à unidade: o que se tem são vários elementos, vindos de diversas partes, constituindo o discurso.

Uma formação discursiva não desempenha, pois, o papel de uma figura que pára o tempo e o congela por décadas ou séculos: ela determina uma regularidade própria de processos temporais; coloca o princípio de articulação entre uma série de acontecimentos discursivos e outras séries de acontecimentos, transformações, mutações e processos. Não se trata de uma forma intemporal, mas de um esquema de correspondência entre diversas séries temporais (FOUCAULT, 1997, p. 82).

O sertão, ainda que seja o espaço lá do interior, é também o tempo e as condições pelas quais o discurso sobre ele é tecido. Essa rede, composta de dispersões que envolvem diferentes enunciados que convivem entre si, conduz a um processo de enunciação que não se repete, pois os tempos - e, ainda, os espaços e as circunstâncias - não são os mesmos. Por isso, o sertão de seca, de veredas, de desenvolvimento, de desigualdades e de possibilidades, percebido nas reportagens de 2012, não é o mesmo dos anos 1950, pois as circunstâncias socioculturais e econômicas da segunda metade do século XX não são as mesmas que estão presentes no início do século XXI, e tais condições impactam a significação do contexto. 
O primeiro desafio para chegar lá [Buritizeiro] (sic) é vencer os 80 quilômetros de estrada de chão. 'Houve dias piores. A energia elétrica só chegou aqui na década de 1990', conta Antônio Ramos, de 66. No mês passado, depois de economizar boa tarde da aposentadoria de um salário mínimo ( $\mathrm{R} \$ 622,00)$, ele pagou $\mathrm{R} \$ 300,00$ por uma imensa antena de televisão. Para os moradores de lá, antena não é luxo. 'Em Paredão, casa que não tem esse tipo de aparelho só tem acesso ao sinal de uma emissora', disse o homem que ainda não sabe quando conseguirá juntar dinheiro suficiente para reforçar as paredes de barro e trocar o desgastado telhado da casa (LOBATO, 2012, p. 14).

Se, naquele tempo, estrada de chão era comum, hoje significa atraso; se televisão era luxo - o aparelho só se difundiu no Brasil a partir dos anos 1960 -, hoje é algo básico. Os "dias piores" são avaliados no presente em comparação com o passado, cujos critérios para definir o que é "bom" ou "ruim" são bastante diferentes dos de hoje: nos tempos em que a energia elétrica era algo distante para muitas regiões, lampião e lamparina eram itens de diferenciação social. Agora, quando usados, significam a condição de miséria.

De acordo com Foucault (1999), a memória discursiva é tudo aquilo que foi ouvido durante toda a vida e que se atualiza conforme quem fala e de onde fala. Percebese, ainda, a formação discursiva, que é esse feixe de relações e interações que formam e envolvem os enunciados, abrangendo o que já foi dito e, ainda, o que pode e o que não pode ser dito a respeito de alguma coisa. Nessa discussão, cabe lembrar ainda do interdiscurso, ou seja, aquilo que está presente no discurso e o relaciona a diversos outros discursos. Segundo Foucault (1999), o interdiscurso e a formação discursiva são constitutivos, ou seja, não podem ser separados, pois um só existe porque o outro existe.

Ainda de acordo com Foucault (1997), diversos procedimentos controlam e delimitam o discurso, aqui entendido como uma dispersão de enunciados, um "conjunto em que podem ser determinadas a dispersão do sujeito e sua descontinuidade em relação a si mesmo. É um espaço de exterioridade em que se desenvolve uma rede de lugares distintos" (FOUCAULT, 1997, p. 62). A dispersão pode ser comparada à poeira que o vento remove ou, ainda, à luz que se propaga na água, transformando os tons e as direções conforme os contornos das ondas. Assim, é possível entender não apenas a dispersão do sujeito, mas, também, a dispersão das palavras como um movimento que as transformam segundo as ondulações que o tempo, os espaços e as circunstâncias possibilitam. Talvez 
por isso, os significados se propagam e se distinguem conforme os lugares e as direções pelos quais se deslocam.

$\mathrm{Na}$ construção dos textos jornalísticos, os enunciados de Grande sertão: veredas se juntam aos enunciados elaborados pela reportagem e o sertão é construído pelo olhar estrangeiro numa zona de contato construída nas relações discursivas que se encontram num limiar, pois:

oferecem-lhe objetos de que ele pode falar, ou antes (pois essa imagem da oferta supõe que os objetos sejam formados de um lado e o discurso do outro), determinam o feixe de relações que o discurso deve efetuar para poder falar de tais e quais objetos, para poder abordá-los, nomeálos, analisá-los, classificá-los, explicá-los, etc. Essas relações caracterizam não a língua que o discurso utiliza, não as circunstâncias em que ele se desenvolve, mas o próprio discurso enquanto prática (FOUCAULT, 1997, p. 53).

Quando se retira algo de algum lugar e o insere em outro, muda-se também a significação. Com a citação acontece o mesmo: o romance foi escrito em determinado momento e sob certas circunstâncias e quando trechos dele são descolados e inseridos em outros textos, os significados mudam.

Em todas as matérias da série "Sertão grande", logo abaixo da vinheta, no alto da página, há uma citação direta do romance Grande sertão: veredas. No caso da reportagem "Pobreza parece mais perene que os rios" (Fig.5), a citação atua como um preâmbulo para introduzir o assunto. "Aquela gente depunha que tão aturada de todas as pobrezas e desgraças. Haviam de vir, junto à mansa força. Isso era perversidades? Mais longe de mim - que eu pretendia era retirar aqueles todos, destorcidos de suas misérias" (ROSA apud LOBATO, 2012, p. 14).

Esse trecho destacado na reportagem refere-se, no romance, a uma passagem em que Riobaldo, como Urutu Branco - chefe de jagunços, faz com que os sertanejos pobres que encontra num vilarejo entrem para o bando em troca de "glórias".

Pois vamos! As famílias capinam e colhem, completo, enquanto vocês estiverem em glórias, por fora, guerreando para impor paz inteira neste sertão [...] - 'Ij' Maria, é ver, nós, de Cristo, jagunceando...' - escutei, dum. Daí, declarei mais: - 'Vamos sair pelo mundo, tomando dinheiro 
dos que têm, e objetos e as vantagens, de toda valia... E só vamos sossegar quando cada um já estiver farto, e já tiver recebido umas duas ou três mulheres, moças sacudidas, p'ra o renovame de sua cama ou rede!' Ah, ô gente, oh e eles: que todos, quase todos, geral, reluzindo aprovação. Mesmo os meus homens. Fiz gesto, com meu contentamento (ROSA, 2006, p. 446).

Figura 5 - Reportagem "Pobreza parece mais perene que os rios"

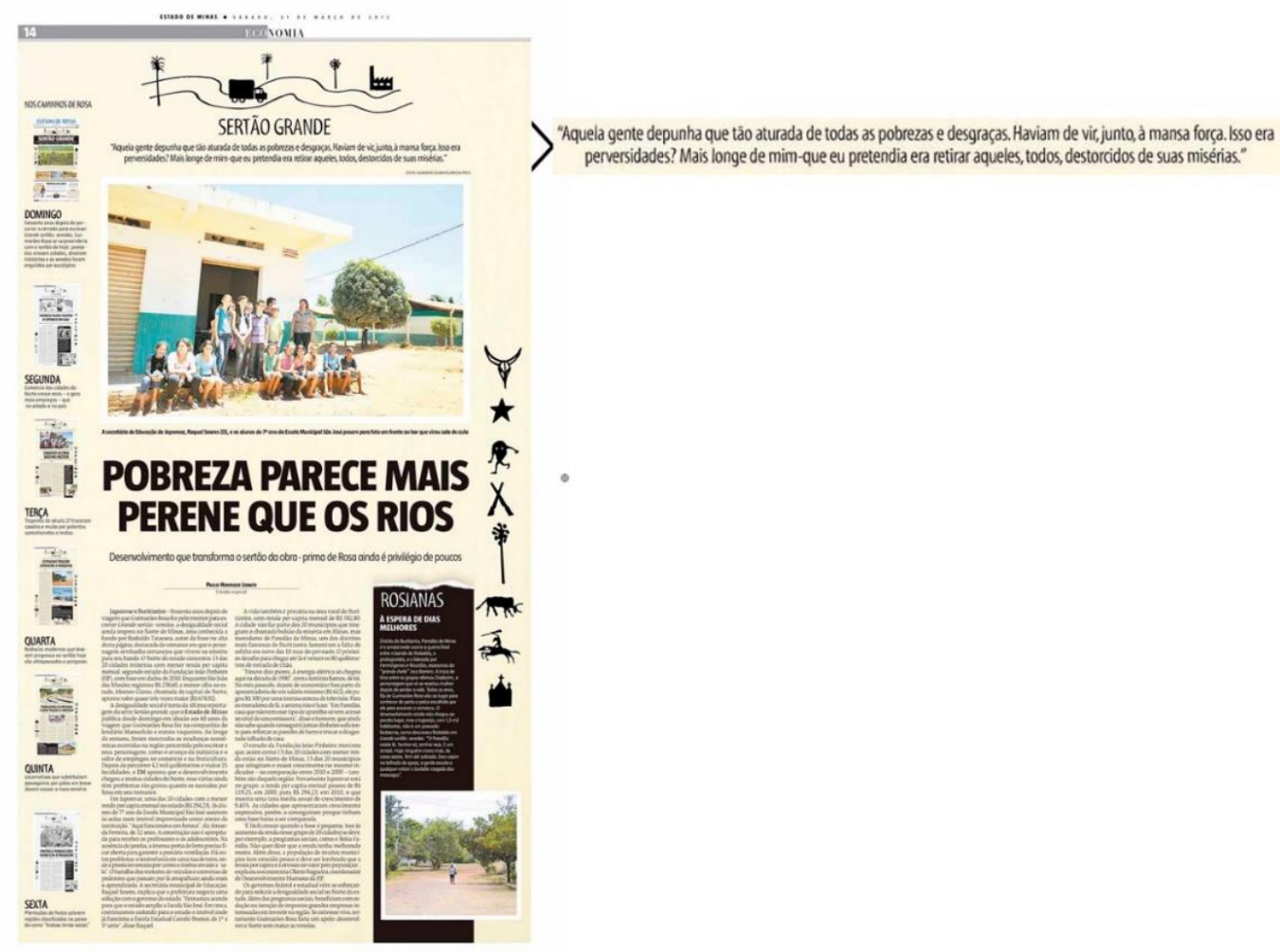

Fonte: Jornal "Estado de Minas", 31 de março de 2012.

No entanto, o que há são promessas falsas que o personagem faz para poder conseguir homens para o bando. Alegoricamente, identificam-se as carências da população para poder explorá-las e convencer as pessoas a fazerem o que o explorador quer. Na reportagem discutida, o efeito de sentido percebido pela interação entre a citação do romance, o título e o texto da reportagem reforçam a percepção sobre a exploração da mão de obra no sertão em ambas as construções textuais e a situação precária das pessoas. “Japonvar e Buritizeiro - Sessenta anos depois da viagem que Guimarães Rosa fez pelo 


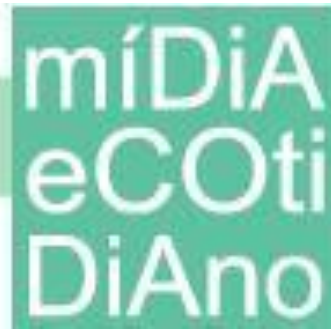

interior para escrever Grande sertão: veredas, a desigualdade social ainda impera no Norte de Minas" (LOBATO, 2012, p. 14).

A formação discursiva remete à miséria e sequidão do sertão, onde os rios perenes jorram lentamente e se arrastam na terra seca, insistindo para não secarem, e também, à ideia de desenvolvimento enquanto melhoria de vida para as pessoas, mas com impactos ao meio ambiente natural. "Além dos programas sociais, [governos federal e estadual] beneficiam com redução ou isenção de impostos grandes empresas interessadas em investir na região. Se estivesse vivo, certamente Guimarães Rosa faria um apelo: desenvolver o sertão sem matar as veredas (LOBATO, 2012, p. 14). Essa tensão pode ser observada, por exemplo, nas fotografias da capa da série (Fig. 6) e na fotografia da última reportagem (Fig.7).

Figura 6 - Capa da série "Sertão grande"

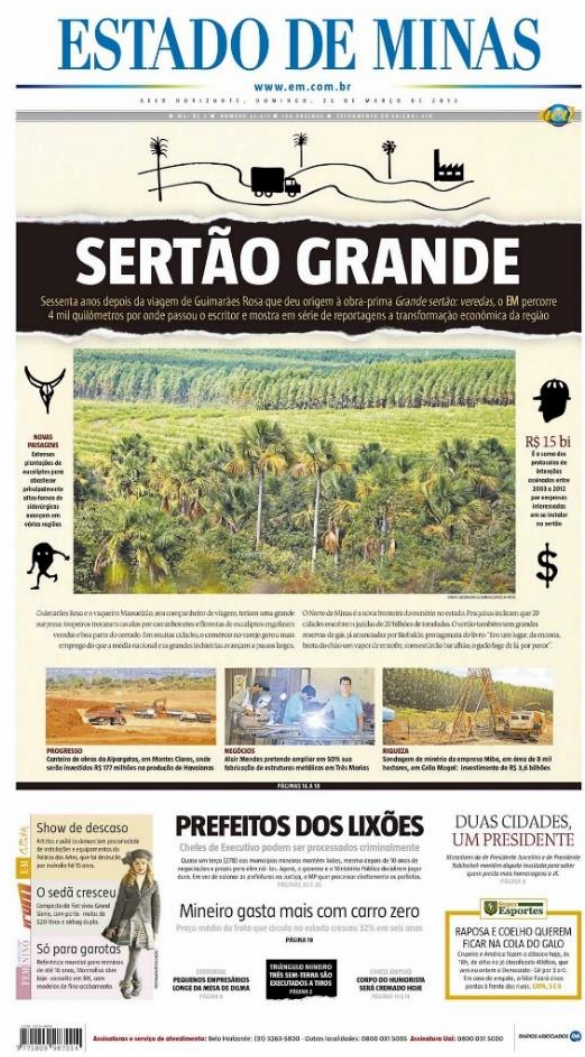

Fonte: Jornal "Estado de Minas", 25 de março de 2012.
Figura 7 - Última reportagem da série

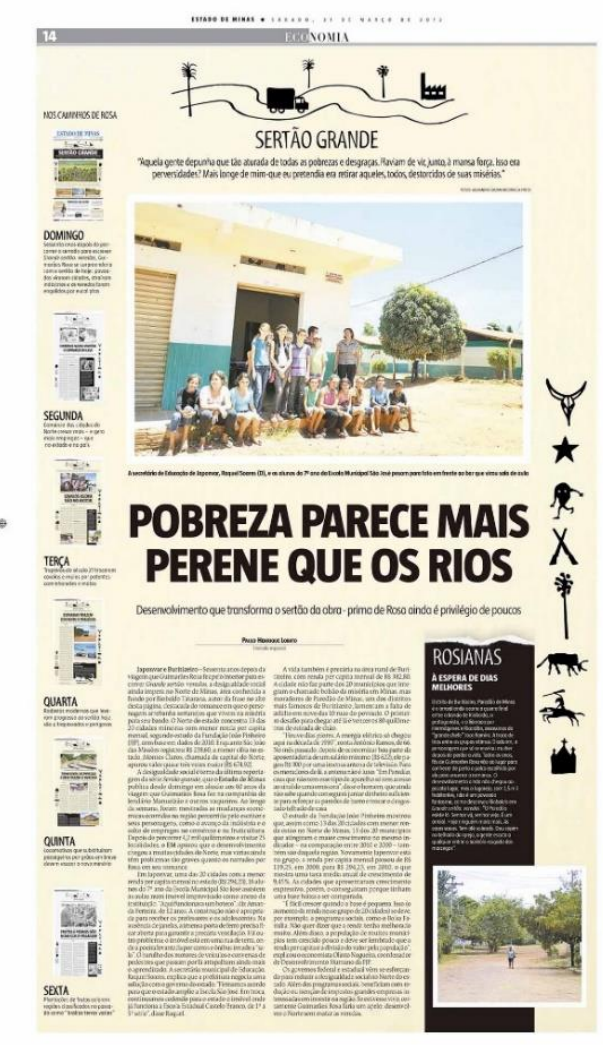

Fonte: Jornal "Estado de Minas", 31 de março de 2012. 
Na Fig. 6, as imagens demonstram a tensão em que o sertão está: na fotografia maior, ao centro da página, as veredas em primeiro plano estão separadas por uma faixa com vegetação rasteira localizada no centro óptico da fotografia e, logo atrás, dividem o espaço com os eucaliptos que se perdem em perspectiva. As três fotografias abaixo são nomeadas, respectivamente, como "Progresso", "Negócios" e "Riqueza", mas onde estão as palavras "progresso" e "riqueza", as imagens mostram a terra devastada pelo trator e, entre elas, a única foto que traz pessoas no trabalho que, por meio da solda, transforma a matéria prima. Em outras palavras, tem-se a tecnologia e o ser humano transformando o sertão.

Já na Fig.7, muitas pessoas posam para a fotografia em frente a uma sala de aula improvisada em um imóvel que, antes, era um bar. Nesse caso, o efeito de sentido referese à dificuldade em ter acesso à educação que, na memória discursiva, prevalece como caminho para melhorar de vida.

Nessas zonas de contato, o que se percebe é um sertão desigual, disperso entre palavras que o ilustram de formas distintas, ainda que semelhante na multiplicidade de espaços e histórias. Assim, sejam as memórias e as viagens, sejam as leituras ou reescritas, o efeito de sentido a que se tem acesso refere-se a um sertão constituído com elementos tanto reais quanto fictícios. Nesse encontro, pelas relações discursivas que, conforme Foucault (1997), caracterizam o discurso enquanto prática, os espaços entre um texto e outro, embora delimitados na forma de descrever os personagens e lugares, se tornam limiar onde surge a terceira margem ${ }^{9}$ do sertão, que reúne o romance e a reportagem num espaço constituído pela linguagem.

\section{Considerações finais}

Palavras dispersas pelos tempos e espaços se assemelham às folhas que se desprendem das veredas e movem-se pelo sertão no ritmo dos ventos e das brisas.

\footnotetext{
${ }^{9}$ A ideia de terceira margem é inspirada no conto de Guimarães Rosa chamado "A terceira margem do rio", publicado no livro Primeiras estórias, em 1962. Sobre o conto, observa-se que é significativo que o espaço escolhido pelo pai seja um espaço terceiro, espaço de mediação, de comunicação entre o visível e o invisível (SOUZA, Lícia Soares. Traduções semióticas em Guimarães Rosa. Acta Semiotica et Lingvistica, v. 14, ano 33, $\mathrm{n}^{\circ}$ 1, Editora Universitária UFPB, 2009, p. 156).
} 
Misturam-se os elementos, modificam-se os tons, transformam-se em outras matérias, difundem-se no cascalho da estrada de chão ou seguem nas correntezas dos cursos d'água que compõem a travessia do espaço de Grande sertão: veredas. Também se difundem no pó do asfalto e das fábricas que chegam ao interior mineiro e na perenidade dos rios que a série jornalística "Sertão grande" lembra.

Seriam as mesmas folhas das mesmas veredas? Em certa medida, sim; em certa medida, não. As folhas continuam folhas, assim como as palavras continuam palavras, mas se transformam. O lugar de onde saem e os redemoinhos pelos quais passam as modificam: a dispersão constrói o discurso conforme as circunstâncias. Daí que o sertão de 1952 e o sertão de 2012, embora delimitem formalmente a fronteira entre ficção e factual dado os gêneros de cada texto, estão num limiar que dilui as divisões para tornar a narrativa uma construção de linguagem.

O sertão que surge da zona de contato entre o texto literário, o jornalístico e o design editorial é um sertão de muitos tons e assim como o movimento das folhas, vai se modificando de acordo com os lugares nos quais se insere e conforme a luz que incide. Há uma tensão que o polariza: sequidão e veredas, progresso e atraso, desenvolvimento e desigualdade. Mas há também, uma pergunta que os mescla: tudo isso em relação a quê mesmo?

No caminho do meio, ou, na terceira margem, o limiar que faz com que a significação de cada um desses conceitos seja compreendida dentro de uma prática discursiva e, com isso, as palavras podem ou não ser o que dizem. O tempo, o espaço e os contextos mudam. Os significados também.

Na zona de contato, é pelo olhar do outro que a significação do sertão acontece: na tessitura das narrativas, as palavras dos personagens do romance e dos personagens das reportagens ganham espaço no texto pelo recorte da grafia do viajante. O sertanejo conta ao estrangeiro sobre a vida no sertão e o estrangeiro, reconta a história de outro lugar. Os deslocamentos se fazem e, nesse movimento, a significação também se movimenta. As respostas não se fecham e o sertão se amplifica. 


\section{Referências}

BOLLE, Willi. grandesertão.br: o romance de formação do Brasil. São Paulo: Duas Cidades; Ed. 34, 2004.

CALDWELL, Cath; ZAPATERRA, Yolanda. Design editorial: jornais e revistas / mídia impressa. São Paulo: Gustavo Gili, 2014.

COSTA, Andriolli. Os caminhos para um pós-jornalismo. Revista do Instituto Humanitas Unisinos, n. 447, ano XIV, São Leopoldo, Rio Grande do Sul, 30 de junho de 2014.

COSTA, Ana Luiza Martins. Via e viagens: a elaboração de Corpo de Baile e Grande sertão: veredas. In: Cadernos de Literatura Brasileira. Edição Especial comemorativa dos 10 anos dos Cadernos de Literatura Brasileira, $n^{\circ} 20$ e 21, p. 187-221. São Paulo: Instituto Moreira Salles, dezembro de 2006.

FOCAULT, Michel. A ordem do discurso: aula inaugural no Collège de France, pronunciada em 2 de dezembro de 1970. Trad. Laura Fraga de Almeida Sampaio. 5. ed. São Paulo: Edições Loyola, 1999.

FOUCAULT, Michel. Capítulos selecionados (As unidades do discurso; As formações discursivas; A formação dos objetos; A formação das modalidades enunciativas; A formação dos conceitos; A formação das estratégias). In: A arqueologia do saber. Trad. Luiz Felipe Baeta Neves. 5. ed. Rio de Janeiro: Forense Universitária, 1997. p.23-85.

GAGNEBIN, Marie Jeanne. Entre a vida e a morte. In: OTTE, Georg; SELDMAYER, Sabrina; CORNELSEN, Elcio (Orgs). Limiares e passagens em Walter Benjamin. Belo Horizonte: Ed. UFMG, 2010. p. 13-26.

HANZEN, Elstor. Novas teorias sobre a produção jornalística. Observatório da Imprensa, edição 877, 23 de novembro de 2015. Disponível em: https://bit.ly/2ygur02. Acesso em: 2 maio 2020 .

LABORATI, Carla; TEIXEIRA, Nincia Ribas Borges. Confluências entre literatura e jornalismo - um estudo de 1968: o que fizemos de nós. Revista Verso e Reverso, v. 23, n. 52, 1\%2009. Disponível em: http://revistas.unisinos.br/index.php/versoereverso/article/view/5788. Acesso em: 10 maio 2020.

LE GOFF, Jacques. História e memória. Trad. Bernardo Leitão et.al. 5. ed. Campinas, SP: Editora da Unicamp, 2003.

LOBATO, Paulo Henrique. Pobreza parece mais perene que os rios: desenvolvimento que transforma o sertão da obra-prima de Rosa ainda é privilégio de poucos. Jornal "Estado de Minas", Série Especial Sertão Grande, Caderno Economia, 31 de março de 2012, p. 14.

LOBATO, Paulo Henrique; RIBEIRO, Luiz. Veredas do novo sertão: riqueza, emprego e tecnologia pintam cores diferentes no cenário de Guimarães Rosa. Jornal "Estado de Minas", Série Especial Sertão Grande, Caderno Economia, 25 de março de 2012, p. 16.

MARTINEZ, Monica; CORREIO, Eduardo Luiz; PASSOS, Mateus Yuri. Entre fato e ficção: personagens compostos e fictícios ou fraude em jornalismo? Estudos em Jornalismo e Mídia, v. $12, \mathrm{n}^{\circ} .2$, p.238-250, julho a dezembro de 2015. Disponível em: http:dx.doi.org/10.5007/19846924.2015v12n2p238. Acesso em: 11 maio 2020. 
OLIVEIRA, Luiz Ademir; CAETANO, Paulo Henrique. A grande imprensa em Minas Gerais: entre o jornalismo institucional e o modelo de gestão empresarial. Anais do $\mathbf{8}^{\mathbf{0}}$ Encontro Nacional da Associação Brasileira de Pesquisadores de História da Mídia, UFRGS, 2011. Disponível em: https://bit.ly/2TpDNhw. Acesso em: 12 maio 2020.

PRATT, Mary Louise. Os olhos do império: relatos de viagem e transculturação. Trad. Jézio Hernani Bonfim Gutierre. Bauru, SP: EDUSC, 1999.

ROSA, João Guimarães. Grande sertão: veredas. Rio de Janeiro: Nova Fronteira, 2006.

ROSA, João Guimarães. Grande sertão: veredas. 22. ed. Rio de Janeiro: Companhia das Letras, 2019.

TRAQUINA, Nelson. Teorias do jornalismo: porque as notícias são como são. vol. 1. 2. ed. Florianópolis: Insular, 2005. 